\title{
Information needs and information seeking behaviour of environmental scientists in universities in Sri Lanka: major issues and concerns
}

\section{Chitrani Gamage}

\section{BA (Hons.) Peradeniya, MSSC (Lib. Sc.) Kelaniya \\ Senior Assistant Librarian \\ University of Peradeniya}

\begin{abstract}
The paper is based on a survey to assess information needs and information seeking behaviour of environmental scientists in universities in Sri Lanka with a view to identify the major issues and concerns which affect their access and retrieval of information. It also examines the feasibility of building up an up to date information resource collection on environmental sciences including print and electronic media and facilitating improved library services beyond the physical boundaries. The major findings of the survey are as follows: Majority of the scientists have pointed out that the library collections of environmental sciences are not up-to-date, collections are not properly stored, available collections are not organized, journals are inadequate and incomplete. The environmental scientists have recommended short term and long term solutions to improve access to environmental information. The environmental scientists have totally agreed that upto- dateness of the collections is as the major issue. Access to electronic resources is also recommended by the respondents. The respondents recommended to organize special environmental collection in main university libraries rather than having separate buildings for environmental sciences. Respondents showed a positive response to establish an environmental information network for university libraries in Sri Lanka.
\end{abstract}

\section{Introduction:}

Global attention has been focused on environmental management since the 1970' $\mathrm{s}$, with the objective to ensure protection of the world from pollution and degradation. Environmental issues has captured the attention of global organizations such as UNEP (United Nations Environment Programme), WHO (World Health Organization) etc. As a result of the world leaders and organizations try to promote a pollution free environment for all living beings, the 
subject environmental science has been developed as a separate discipline. In Sri Lanka, the scientists who are involved with environmental work have drawn from environmental related disciplines such as geography, geology, engineering, chemistry, agriculture, economics etc. The subject environmental science has been introduced to university education in 1990's with the inception of study courses at University of Rajarata and PGIA, the Postgraduate Institute of Agriculture, University of Peradeniya. But certain aspects of environmental sciences were included in the university curricular with other subjects prior to that. In this context it is essential to identify the information needs, information seeking behaviour and the major issues and concerns of environmental scientists, which has an impact on environmental science education and research of the country. Information gathered from this study will be useful to develop up to date information resource collections in universities and to have an improved library and information services to the university community. Although environmental science is offered as a separate discipline in universities the university libraries lack up to date collections on environmental sciences to facilitate teaching learning and research.

Information is a vital source for productive use. Scientific information is communicated by scientists mainly through scientific reports, research articles and papers presented at conferences, or at discussion forums, dialogues at seminars and workshops. The development of information, communication and technology (ICT) and the advent of the Internet have enhanced the availability of information in scientific disciplines including environmental sciences. But even at the present day most of the scientists in developing countries are depending on printed materials to obtain current information.

\section{Objectives of the Study:}

The objectives of the study are noted below.

I. To Identify major issues and concerns of environmental scientists in the universities in Sri Lanka, which affect the information seeking behaviour of them.

II. To find out the feasibility of establishing a separate library or a collection for environmental scientists in universities in Sri Lanka.

III. To find out the types of information services required by them.

\section{Methodology:}

A questionnaire based survey was conducted to identify the information needs and information seeking behaviour of environmental scientists backed up by secondary information, Key Informant Survey and self observations. 
Respondents of the study were selected mainly from the following sources.

(1) Directory of Environmental Expertise in Sri Lanka 1994, published by the Central Environmental Authority of Sri Lanka

(2) The data base produced by the National Science Foundation in Sri Lanka

(3) Personal contacts

Thirty five questionnaires were distributed among the environmental scientists in thirteen universities in Sri Lanka. Eighty six per cent (86\%) questionnaires duly completed and returned from nine universities. Out of the responded universities, Rajarata University of Sri Lanka is conducting special and general degree programs on Environmental Management and Environmental Sciences. Postgraduate courses on Environmental Economics and Natural Resource Management are being conducted at the Post Graduate Institute of Agriculture of the University of Peradeniya.

\section{Results and Discussion:}

\section{Qualifications of the respondents:}

The qualifications of respondents can be categorized into three groups. The highest percentages of the respondents $(57 \%)$ are $\mathrm{PhD} / \mathrm{D}$.Sc qualified while thirty percent $(30 \%)$ have Masters degrees. However, thirteen percent of the respondents had Bachelors degrees (Figure 1.0).

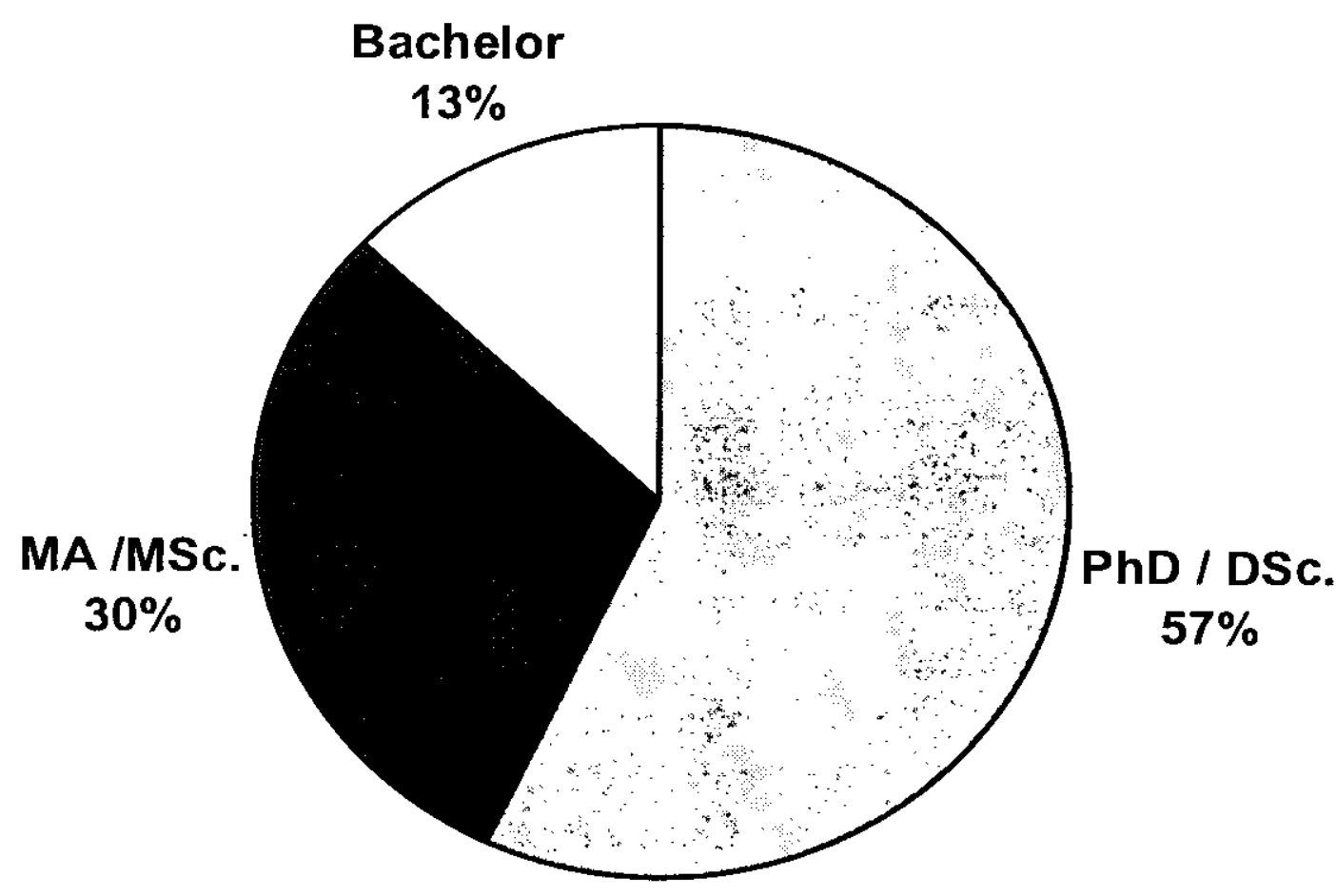

Figure I. Qualifications of the Environmental Scientists 


\section{Areas of Subject Specialization:}

Information was collected on areas of subject specialization to identify the information needs. The data revealed that the highest percentage $(51 \%)$ of scientists are specialized in Environmental Policy and Management. The second highest number was (22\%) reported from Water Management studies. Environmental resources, which includes the subject areas Ecosystems and Environmental Control, Forest Influences, Habitats and Landscape are next in line with seventeen percent $(17 \%)$ of scientists. Other fields which includes Aquatic Environment, Social Environment and Urban Environment cover ten percent $(10 \%)$ of scientists (Figure II.0).

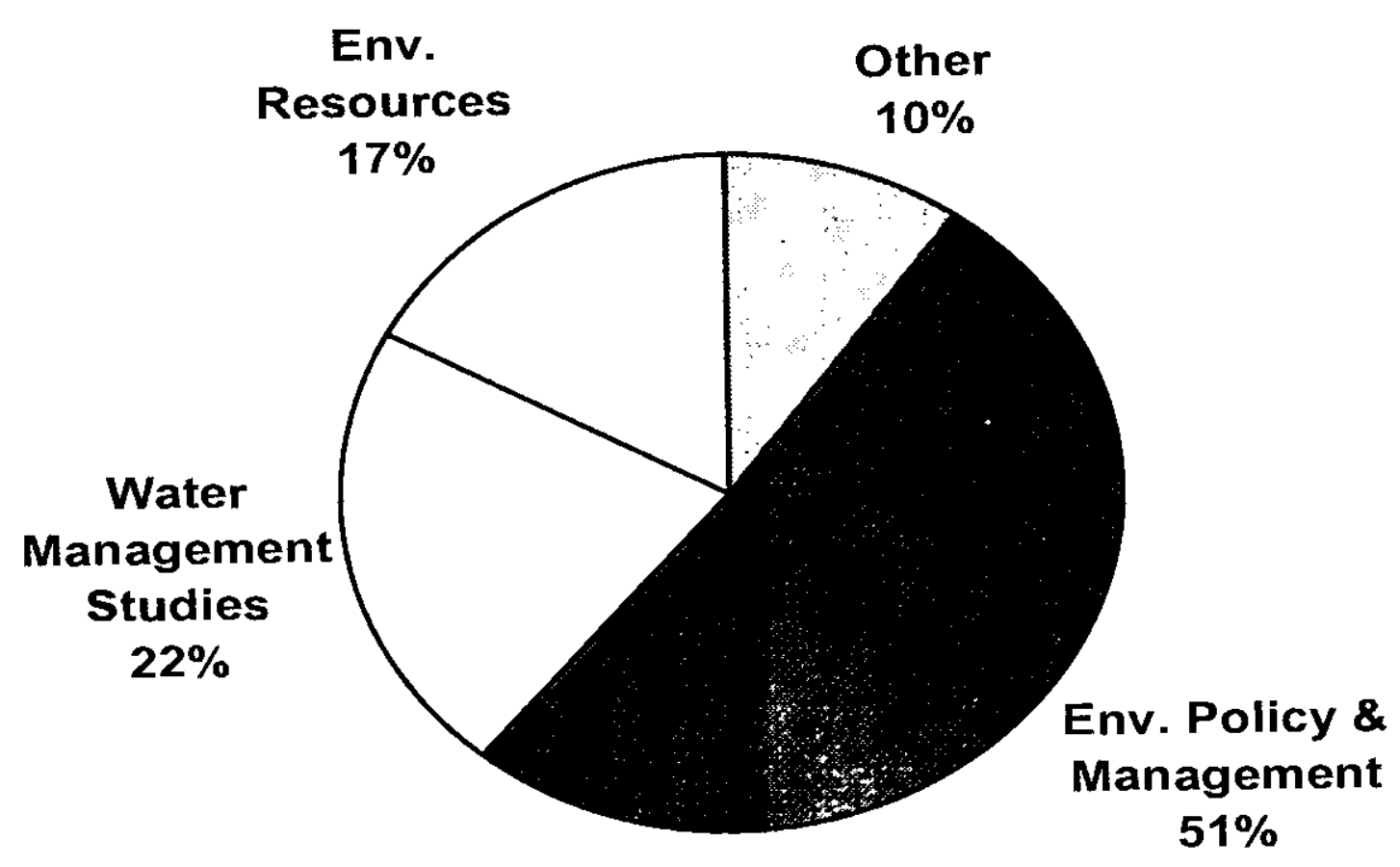

Figure 2: Areas of Subject Specialization

Further the analysis of the research interests of respondents show that the scientists fall into 21 disciplines related to environmental sciences. The highest number of scientists (33\%) are engaged in Water related studies, basically due to agricultural and land development projects, which are in progress. Thirty percent $(30 \%)$ of the scientists are engaged in Environmental Management and Policy. Their researches have influenced many government policy matters. Environmental Assessment includes $7 \%$ of the scientists. According to the study, the number of scientists involved in research on Environmental Pollution is minimal which is a very controversial finding although politicians and policy makers are constantly paying attention to this issue, and try to take remedial measures to curtail environmental pollution. 


\section{Categories of Work Performed by University Environmental Scientists:}

Environmental scientists are engaged in different categories of work other than teaching and research. Figure number three shows the responses given by the scientists, listing the categories of work that they are involved. The majority $(67 \%)$ of university environmental scientists are engaged in teaching and research. $20 \%$ are involved in environmental projects while $13 \%$ are doing consultancies.

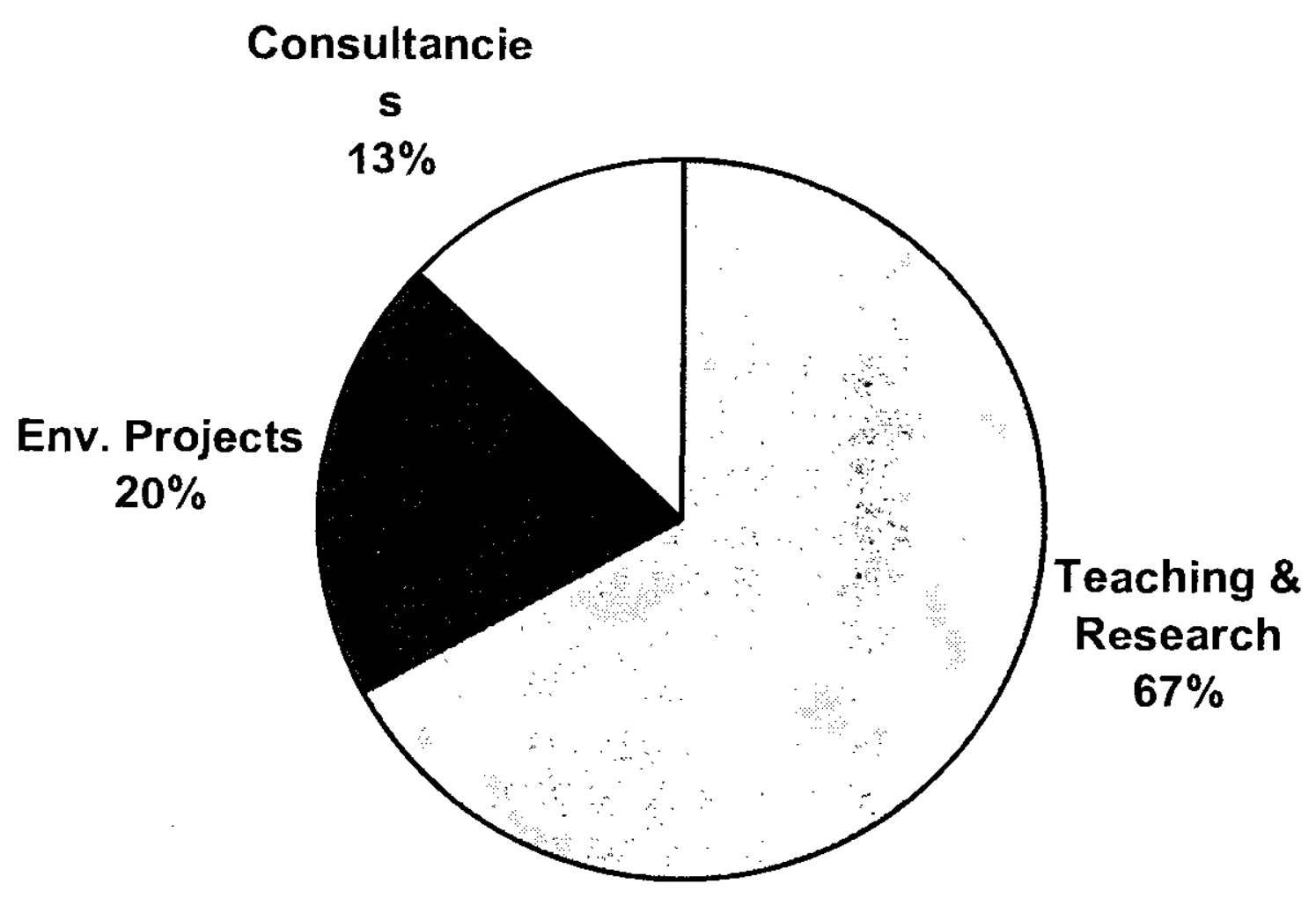

Figure 3 Categories of work

Since, environmental scientists require information to perform a wide variety of tasks

as mentioned above it is necessary for the information professionals or the librarians to identify their information needs and look into their information seeking behaviour. "Information professionals should be partners of users, who provide them with support, advice and training with respect to information seeking patterns" (Steinerova 2001)

\section{Information Needs, Seeking Behaviour and Purpose of Seeking Information:}

Information needs of environmental scientists can be assessed by identifying the purpose of seeking information. This is a common concept used for user studies. In this study, environmental scientists were asked to rank five main reasons for 
using the library, according to the priority needs of their work. Since academics are expected to improve their knowledge for teaching and research; the environmental scientists identified their purpose of seeking information according to the following order.

1. To keep up with current development.

2. To develop competence.

3. To support research work in progress.

4. Teaching.

5. Other professional work such as Consultancies.

Environmental scientists use different information sources, when they need information to carry out various tasks, which are noted below.

1. At the beginning of a research project.

2. Writing a paper to present at a conference.

3. Deliver a special lecture at seminars and workshops.

4. To prepare for teaching students in universities.

All the sources they use to satisfy their information needs can be divided as formal, semi formal and informal. According to the study, periodicals/ journal reviews, abstracts, indexes, bibliographies are the most important formal sources. Most of the environmental scientists frequently use the Internet facilities, computer data bases and CD-ROMS etc. to obtain current information. ICT (Information Communication Technology) facilities are not available in most of the new universities due to the high cost of electronic resources and infrastructure, mainly as a result of low funding even though environmental study courses are offered at certain universities. Other information materials such as, maps and gazetteers are very useful for the work conducted by the environmental scientists in universities. But, these tools available in university libraries are outdated and less useful. All these sources used by them are examined under four approaches namely; current approach, everyday approach, exhaustive approach and brush up old speciality approach, to assess the effectiveness of these sources.

\section{Major Issues and Concerns in Seeking Information:}

Information needs of scientists are generally specific, which is no exception to environmental scientists too. All university libraries in Sri Lanka are not selfsufficient with their resources to meet information needs of clients who seek information. Environmental scientists have identified the major drawbacks or the issues and concerns which adversely affect their information seeking behaviour according to the priority order given below.

1. Collections are not up to date.

$87 \%$

2. Collections are not properly stored.

$80 \%$

3. Available collections are not organized, (catalogued, classified or indexed) 
4. Periodicals and journals are inadequate and incomplete. $67 \%$

As a result of the above mentioned drawbacks environmental scientists have to work under extreme difficulties and most of them are unable to complete current research work on time. Among the major drawbacks identified by the environmental scientists, the up to dateness of the collections and the inadequacy and incompleteness of the periodicals are mainly due to financial constraints in university libraries. The cost of books and journals are increased every year. The university libraries have severe constraints in meeting the increasing cost of information resources. As a result, current books on environmental sciences, current journals, bibliographic tools such as indexes, abstracts, bibliographies etc. in print or electronic media cannot be regularly acquired by university libraries. The paucity of information resources does not facilitate environmental scientist to engage in teaching and undertake important research work which are needed for the country.

Further the environmental scientists have commented that the available environmental resources in libraries are not properly organized for easy access to information, which also has adversely made and impact on the information seeking behaviour of environmental scientists in Sri Lanka.

\section{Suggestions for the Development of Environmental Resource Collections:}

Table 1.0 presents the views of all respondents for improving the environmental collections in university libraries. The table shows that most of the environmental scientists have positive interests to develop the collections in university libraries.

\section{Table 1.0 - Suggestions for the Development of Resource Collections}

\begin{tabular}{|l|c|}
\hline \multicolumn{1}{|c|}{ Sequence of Priority } & Reported Values \\
\hline 1. Collections should be up to date & $87 \%$ \\
\hline 2. Should acquire periodicals \& journals continuously & $70 \%$ \\
\hline $\begin{array}{l}\text { 3. Should have separate collection of books \& } \\
\text { periodicals }\end{array}$ & $30 \%$ \\
\hline 4. Maps, Research reports should be available. & $20 \%$ \\
\hline 5. Develop collections through information links & $17 \%$ \\
\hline 6. Develop theses collections on environment & $10 \%$ \\
\hline 7. Consult the scientists for selection of materials & $07 \%$ \\
\hline 8. Bibliographic tools indexes should be available & $07 \%$ \\
\hline
\end{tabular}

Eighty seven percent $(87 \%)$ of the environmental scientists emphasize that environmental collections in university libraries should be updated regularly. 
Seventy percent $(70 \%)$ of the scientists have commented on the continuation of periodicals and journals which are required by them. The need of a separate collection of books and periodicals has been identified as a positive requirement for developing environmental collections by thirty percent of scientists. Twenty percent of the scientists have commented on the availability of maps and research reports needed for their information requirements. Establishing information exchange links through local and international organizations for improving the availability of information for environmental scientist have been identified by seventeen percent $(17 \%)$ of scientists. The other important suggestions made by environmental scientists are, to develop their collection on environment with ten percent of respondents, consultation of scientist for selection of materials and availability of bibliographic tools which consists of seven percent of respondents each.

Further the suggestions made by the environmental scientists can be broadly categorized into four areas, such as acquisitions, organization of information resources buildings and staff.

\section{Acquisitions:}

A good acquisition policy is needed to acquire environmental information to the libraries in Sri Lankan universities. According to the table 1.0, eighty seven percent $(87 \%)$ of the scientists were concerned about the issue of uptodateness of the information resource collection which will be essential to meet their information requirements. The uptodateness of information is vital for the environmental scientists to broaden their knowledge for undertaking teaching and research. Acquisition of current periodicals regularly is a challenge for the librarians with limited funds but it is of highest priority of environmental scientists to embark on quality research and development which are needed in the present context.

\section{Organization of Information Resources:}

Environmental scientists need free and fast access to information. A majority of the environmental scientists emphasized the need of computer databases and online public access catalogue (OPAC) and the Internet for them to access and retrieval of information. A large number of scientists have commented on having a standard classification scheme for organizing environmental resource collections in university libraries. It will be very helpful for the environmental scientists to access information, if there is a standard classification scheme adopted by all university libraries it will be very helpful for the environmental scientists to access the information. Environmental scientists have stressed the importance of having electronic journal packages which contain full text of articles. They prefer electronic media as they are fast in accessing and delivery of information. 


\section{Buildings:}

The environmental scientists in academic institutions did not have an interest in having a separate building for environmental resources. But they prefer space available for a separate collection in existing library buildings where they can use materials freely.

\section{Staff:}

The environmental scientists have commended on dynamic and professional staff with knowledge in environmental sciences for the development of collection and provision of quality service.

\section{Recommendations:}

Two types of solutions can be recommended in order to overcome the difficulties faced by the environmental scientists. First, long term solutions are necessary to improve and develop the environmental resource collections within the entire system. Second, short-term solutions are also necessary as temporary adjustments to maximize the facilities and the library services. Proper planning and management is imperative to increase the efficiency and to provide better services with the available resources. For that purpose, exploration by evaluation and assessments can be done in the existing system to identify the weaknesses and strengths in the short-run, it is the way to avoid the predicament in the system. Introducing a proper classification scheme, organizing a separate resource collection with sufficient space should also be looked into. Extending the opening hours of libraries on weekdays and weekends can be identified as a short term solution.

The present study indicates the existence of some areas where the efforts may be concentrated. In the long-run perspectives, updating collections, provision of computer data bases with free access, the internet and e-mail facilities, professional development of librarians, and establishing a network with international libraries and other institutions can be identified as major factors to overcome the difficulties and facilitate availability of information to the environmental scientists.

It is essential to identify the information requirements of environmental scientists in order to provide improved library services. Identification of information needs further helps to form would workable acquisition policies of libraries.

It is recommended that an environmental information networks be established in Sri Lanka incorporating all university libraries for sharing information resources. Further to that, information links have to be developed by librarians with international organizations such as UNEP, FAO (Food and Agriculture Organization), and Asia Foundation to obtain publications and funds to improve 
the library services. At the national level, librarians should build up contacts with environmental experts for obtaining their publications.

\section{Conclusion:}

The study clearly shows that rearrangement and expansion of the institutional structure is needed to give an efficient service to the environmental scientists promptly. The study also pronounces that the short term and long term strategies are needed in minimizing the short comings. Further to that it suggests the existence of some areas where the efforts may be concentrated.

\section{References:}

Central Environmental Authority of Sri Lanka (1994). Directory of Environmental Expertise in Sri Lanka: Colombo: Ministry of Transport, Highways, Environment \& Women's Affairs

Clancey, W.J. (1996). Knowledge, practice, activities and people.

Paper presented at the AAAI Spring Symposium on Artificial Intelligence in Knowledge Management

http://cogprints.ecs.soton.ac.uk/archive/00000444/00/146.htm Accessed on 21/09/2004

Gamage, U.G.C.C. (1999) Information needs and information seeking behaviour of environmental scientists in Sri Lanka. MSsc Thesis, University of Kelaniya

Mudannayake, Irangani (1987) Information needs and information practices of Agricultural Scientists in Sri Lanka. MLS Thesis, University of Philippines

Steinerova, Jela. (2001) Human issues of library and information work Information Research, 6 (2).

http://InformationR.net/ir/6-2/paper95.html Accessed on 20/09/2004

World Commission on Environment \& Development, 1987. Our Common_Future. Oxford: Oxford University Press. 